\title{
The Religious-Folklore Story of Talking Ant and Solomon: \\ Its roots in natural behaviors of ant colonies
}

Mohammad Reza Besharati, Sharif University of Technology, Tehran, Iran, besharati@ce.sharif.edu

Mohammad Hasan Rouhani, QM Research Center, Shahid Beheshti University, Tehran, Iran

\begin{abstract}
In the logic of the Qur'an and the hadiths, all animals and beings have intellect, understanding and consciousness, but we are unaware of that. Based on the hadiths and folklores, the ant of Solomon, has said very deep and wise things like a great scientist and philosopher. In a way that Prophet Solomon, who himself had a lot of knowledge, according to the hadiths, asked him to preach. Ants have an interesting and complex social life and these folklore stories could have a root in their natural abilities: In order to be able to continue their social life in this way, ants use various methods to communicate and coordinate among themselves.
\end{abstract}

Keywords: Ants, Solomon, Talk, Acoustic Communication

\section{The first theme}

Ants have an interesting and complex social life. In order to be able to continue their social life in this way, they use various methods to communicate and coordinate among themselves [2]. They can communicate in the following four ways:

1- Chemical-olfactory: It means that ants send different messages to each other by releasing different chemical molecules in the air.

2- Speech-auditory: It means they talk to each other by voluntarily producing different sounds, each of which having a specific meaning.

3- Motor-visual: It means that by performing gestures, signs and maybe a kind of pantomime, they give messages to each other.

4- Behavioral - Cooperation: It means that they understand the group state through each other's behavior and cooperate with each other. 


\section{The second theme}

The ant's body is made up of three parts including: the head, the chest and the abdomen. Scientists estimate the number of different species of ants at more than 15,000 , and hope to increase the number of different discovered species of ants to more than 20,000 in future years. Biologists consider ants to be one of the most successful species on the planet Earth because they can overcome the various problems they have had or have in their natural life and environment, and can adapt themselves to the biological and natural conditions very well. One of the abilities that God has given ants, when creating them, is the communication abilities of them. For example, many species of ants can voluntarily produce different and meaningful sounds (for other ants) through organs that specialize in producing and amplifying sound (as well as vibration). These species of ants can also sense tremors and sounds in the air and translate them into nerve signals through the tentacles, as well as layers of epithelial and nerve cells in their knees and tentacles (known as Johnston's organ).

\section{The third theme}

Until the second half of the twentieth century, scientists had little knowledge of ant communication methods. In the middle of the twentieth century, details of the chemical language of insects that work by sending chemical molecules into the air were gradually discovered. Also in the last fifty years, scientists have discovered that many species of ants can voluntarily produce sound and vibration. Powerful electron microscopes, which were made available to entomologists in the late twentieth century, enabled them to discover interesting details of the sound-producing and vibrating organs in ants' bodies. It was only in the last 40 years that some scientists have claimed to be sure that some species of ants can communicate with each other through the production of vibrations and voluntary sounds. In 2000, two scientists wrote an article claiming that ants could talk to each other using phonetic words [2]. Research studies conducted by scientists in later years showed that in addition to a chemical language (which works by sending chemical messenger molecules to each other), ants also have a spoken language that has alphabets, words, accents, and dialects [2], [3], and [4]. And through this spoken-vibrating language, they voluntarily talk to each other, and send messages and communicate with each other [5], [6], and [7]. You can see some of the language words of one of the ant species in the figure-1. 
(a) No. 1 Alarm Stridulation by Many Ants

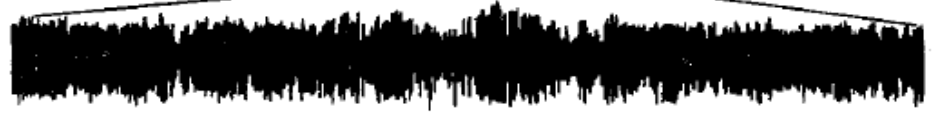

(b) No. 2 Group Awareness

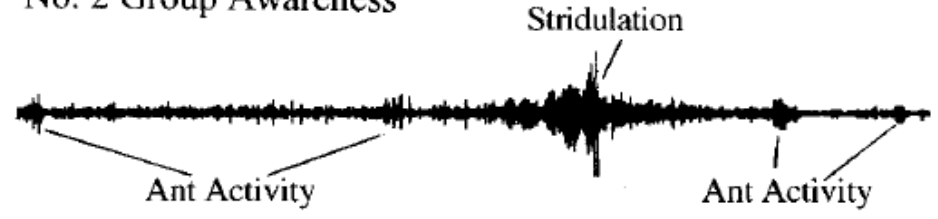

(c) No. 3 Attack

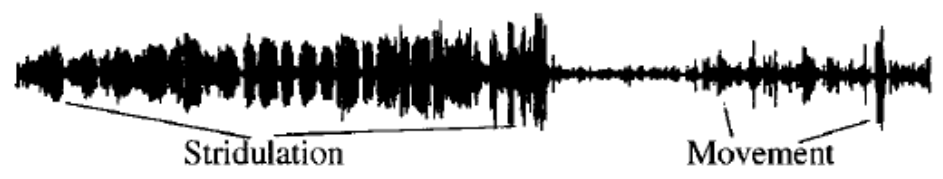

(d) No.4 Distress

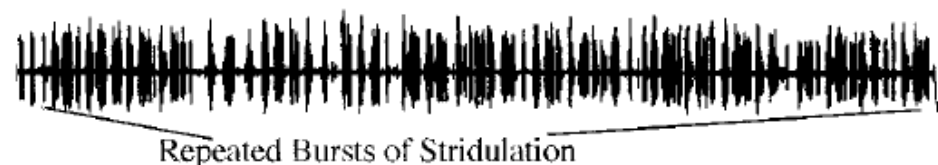

8 Seconds

Pressure-time traces of stridulatory signals of S. richteri (a) No. 1-Alarm signal due to insertion of microphone probe in mound; (b) No. 2-Sounds of normal activity with occasional stridulatory signal; (c) No. 3-Attack on caterpillar and (d) No. 4-Distress signal from ant with caught antenna.

Figure 1-some ant's words. from [2].

\section{The fourth theme}

The Holy Qur'an explicitly states ants' speaking ability and the details of the words in their language. Entomologists in the twentieth century have discovered this scientific fact, a fact that was stated by the Holy Quran 1400 years ago. This is one of the obvious scientific wonders of this divine book. 


\section{The fifth theme}

Allameh Tabatabai (pbuh), who is one of the greatest commentators of the Holy Quran, while interpreting this noble verse, points to the amazing power of the senses of some animals and insects (which have been discovered by experimental science). He considers the speech of the ant in this noble verse to be a real speech (ie, a real speech and not an allegorical one).

It is interesting that 1000 years ago, people were surprised to read this verse and were faced with the mental question "do ants also talk?" They went to the great sage of their time (ie Seyyed Morteza) and asked for guidance in this regard. This historical point shows us that the ancient people were amazed that a small animal like an ant had such great abilities and powers that it could talk to its species and build a complex and strong society to overcome adversities existing in his living environment. But today, we know that the Holy Qur'an has various scientific wonders, and that 1400 years ago, when it announced that ants speak in detail, it can be a sign to us of the greatness of this divine book to increase our faith and insight. The commentators and scholars of Quranic sciences try to have a deep understanding and correct knowledge of the meaning of the words of the Holy Quran, so that they can reflect on the principles and criteria of interpretation of this divine book and better understand its profound meanings. Among the important words of this holy verse, the following terminologies can be mentioned:

1- Land, valley and mountain slopes, places of water flow through lowlands and highlands

2-قالت:

3- نمله: $\quad$ an ant

4- مساكنكم: $\quad$ your places of residence, your nests

5- لا يحطمنكم: Do not crush you, do not break you.

6- و هم لا يشعرون: while they are not aware, while they are not cognizant, while they are heedless. They do not know.

\section{The sixth theme}

Prophet Sulayman (Solomon) lived about 3000 years ago, and is one of the great divine prophets. He had a world government in which he ruled over all humans and animals and had a large and strong army of humans, animals and other creatures. 
God had given him a lot of knowledge and wisdom so that he could rule over all beings with justice and piety.

Abundant power and world government was a divine miracle that God had given him to guide the mankind. Among the many abilities that God gave to Sulayman (pbuh) was his power to understand the language of birds and other creatures (including: ants).

\section{The seventh theme}

... In the logic of the Qur'an and the hadiths, all animals and beings have intellect, understanding and consciousness, but we are unaware of that. Based on the hadiths, the ant of Prophet Sulayman (pbuh), has said very deep and wise things like a great scientist and philosopher. In a way that Prophet Sulayman (pbuh), who himself had a lot of knowledge, according to the hadiths, asked him to preach... The ant said: Do you know why God has brought the wind at your command? To take the advice that your world government and powerful domination is nothing comparing to the power of God: your government is built on the wind and is fixed on the wind, so do not be proud of yourself...This is the way all the good and righteous servants of God, who always consider themselves a small servant before God, act and do not become proud and arrogant.

\section{The eighth theme}

In this figure, you can see a plastic model of the actual structure of an ant colony nest. Dozens of halls, dozens of rooms and numerous tunnels have formed this "large underground residential complex". The multiplicity of rooms and halls, with their diversity of uses, may be able to guide us to a better understanding of the meaning of the word "my dwellings". What is your opinion? 


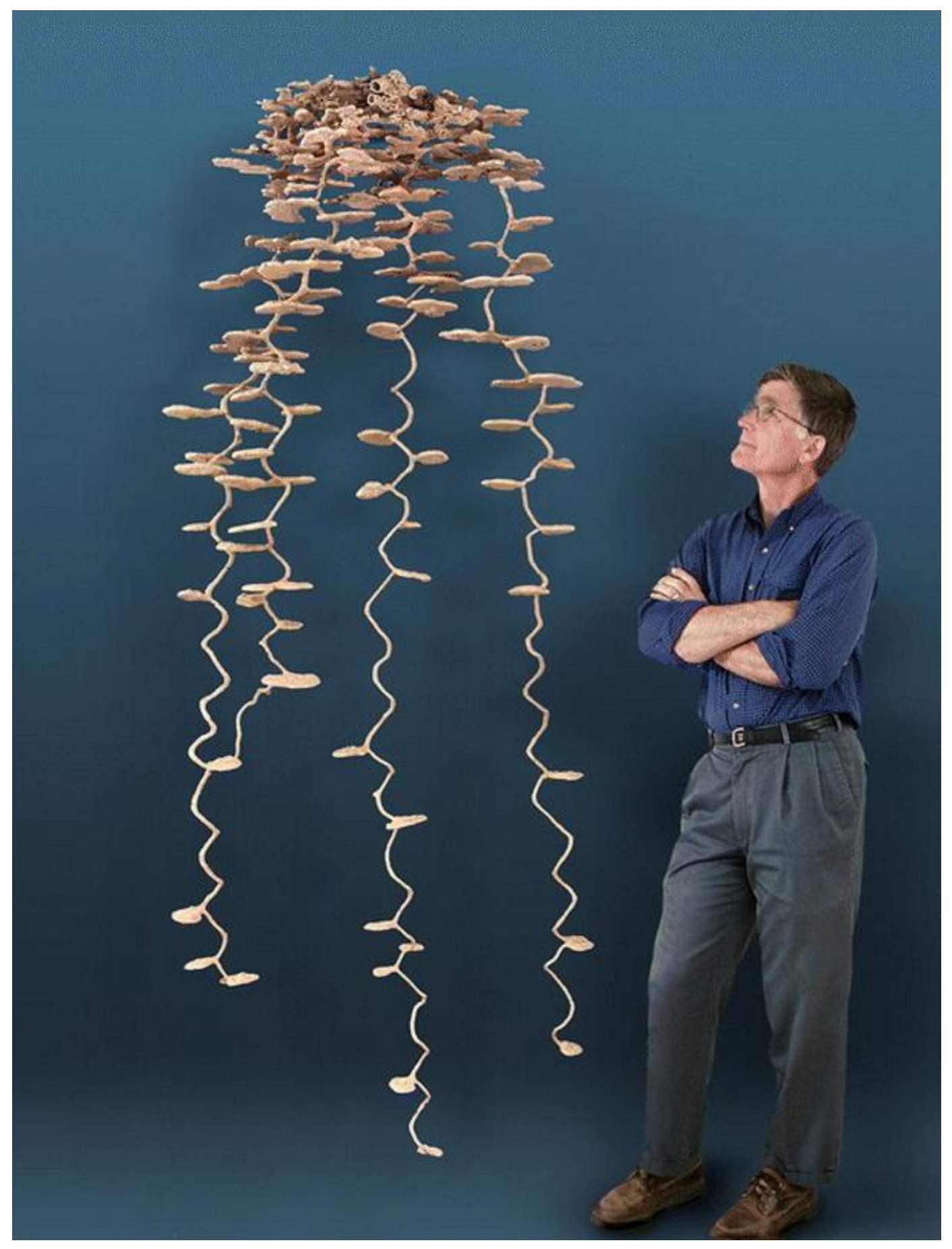

Figure 2- a plastic model of an ant colony nest, made from a real world colony. from Wikipedia [8]. 


\section{$\underline{\text { References }}$}

[1] Holy Quran

[2] Hickling, Robert, and Richard L. Brown. "Analysis of acoustic communication by ants." The Journal of the Acoustical Society of America 108, no. 4 (2000): 1920-1929.

[3] Hunt, J. H., and F-J. Richard. "Intracolony vibroacoustic communication in social insects." Insectes Sociaux 60, no. 4 (2013): 403-417.

[4] Jackson, Duncan E., and Francis LW Ratnieks. "Communication in ants." Current biology 16, no. 15 (2006): R570-R574.

[5] Barbero, Francesca, Jeremy A. Thomas, Simona Bonelli, Emilio Balletto, and Karsten Schönrogge. "Queen ants make distinctive sounds that are mimicked by a butterfly social parasite." Science 323, no. 5915 (2009): 782-785.

[6] Schönrogge, K., Francesca Barbero, L. P. Casacci, J. Settele, and J. A. Thomas. "Acoustic communication within ant societies and its mimicry by mutualistic and socially parasitic myrmecophiles." Animal Behaviour 134 (2017): 249-256.

[7] DeVries, P. J., R. B. Cocroft, and J. Thomas. "Comparison of acoustical signals in Maculinea butterfly caterpillars and their obligate host Myrmica ants." Biological Journal of the Linnean Society 49, no. 3 (1993): 229-238.

[8] https://en.wikipedia.org/wiki/Ant_colony\#/media/File:Ant_Nest.jpg 